\section{A Unique and Scalable Model for Increasing Research Engagement, STEM Persistence, and Entry into Doctoral Programs}

\author{
Nadia Sellami, ${ }^{\prime \ddagger}$ Brit Toven-Lindsey, ${ }^{\S}$ Marc Levis-Fitzgerald, $\$$ Paul H. Barber," \\ and Tama Hasson ${ }^{\text {t* }}$ \\ +Undergraduate Research Center-Sciences, ${ }^{\circledR}$ Center for the Advancement of Teaching, University \\ of California, and "Department of Ecology and Evolutionary Biology, University of California, \\ Los Angeles, Los Angeles, CA 90095
}

\begin{abstract}
Low persistence in science majors and limited participation in high-impact research experiences contribute to the nationwide underrepresentation of minorities in the science workforce, particularly jobs requiring a graduate degree. The Program for Excellence in Education and Research in the Sciences (PEERS) is an academic support program at the University of California, Los Angeles (UCLA) that supports first- and second-year science majors from underrepresented and underserved backgrounds to maximize student success and science, technology, engineering, and mathematics (STEM) persistence. Here, we evaluate the success of PEERS through data from the UCLA registrar, student surveys, and longitudinal tracking of student outcomes. Results show that PEERS students have significantly higher participation rates in undergraduate research, despite PEERS having no formal research component. Importantly, PEERS students were seven times as likely to enroll in PhD programs, and twice as likely to enroll in MD programs compared with propensity-matched controls. Combined results show that increased success of PEERS students in their first 2 years as science majors resulted in improved outcomes later in their undergraduate studies and had tangible impacts on subsequent educational trajectories that will increase participation of underrepresented groups in high-skill STEM careers.
\end{abstract}

\section{INTRODUCTION}

Science, technology, engineering, and mathematics (STEM) fields are major drivers of economic growth, creating a consistent demand for a skilled STEM labor force (President's Council of Advisors on Science and Technology [PCAST], 2012). While demand for STEM graduates is increasing, the rate at which graduates are produced by U.S. colleges and universities lags behind the needs of the U.S. STEM economy (National Academy of Sciences, National Academy of Engineering, and Institute of Medicine [NASEM], 2011; Allen-Ramdial and Campbell, 2014). A major reason for this deficit is that, nationwide, only $28 \%$ of students entering bachelor's degree programs select STEM majors, and only $48 \%$ of these students will complete a STEM degree (Chen and Soldner, 2013).

While these numbers are concerning, persistence rates of underrepresented minority students (URM; African American, Latino/a, Chicano/a, Native American, Pacific Islander) are more troubling. URMs are just as likely as non-URM students to pursue STEM majors, yet they leave STEM majors at twice the rate of non-URM students (Crisp et al., 2009; NASEM, 2011). As a result, URMs only make up $13 \%$ of the STEM workforce, despite constituting $28 \%$ of the U.S. population (NASEM, 2011; Estrada et al., 2016; National Science Foundation [NSF], 2020).
Graham Hatfull, Monitoring Editor Submitted Oct 1, 2020; Revised Nov 20, 2020; Accepted Nov 24, 2020

CBE Life Sci Educ March 1, 2021 20:ar11 DOI:10.1187/cbe.20-09-0224

FPresent address: Department of Medical Education, Keck School of Medicine of USC Los Angeles, Los Angeles, CA 90089. *Address correspondence to: Tama Hasson (thasson acollege.ucla.edu).

(C) 2021 N. Sellami et al. CBE-Life Sciences Education @ 2021 The American Society for Cell Biology. This article is distributed by The American Society for Cell Biology under license from the author(s). It is available to the public under an Attribution-Noncommercial-Share Alike 3.0 Unported Creative Commons License (http://creativecommons.org/licenses/ by-nc-sa/3.0)

"ASCB®" and "The American Society for Cell Biology $\circledR^{\prime \prime}$ are registered trademarks of The American Society for Cell Biology. 


\section{Factors Contributing to URM STEM Persistence}

Many factors contribute to high STEM attrition of URM students. URM students are more likely to struggle with the challenging transition from high school to college, a pattern that partially results from URM students being more likely to be first-generation college students (Choy et al., 2000; Chavira et al., 2016). Once in college, URM students experience an academic culture and climate that can be unwelcoming, discouraging many from continuing in STEM majors (Beasley and Fischer, 2012). Furthermore, many students struggle in their introductory science and math courses due to insufficient high school preparation, resulting in higher attrition rates (Elliott et al.,1994; Strenta et al., 1994; Kokkelenberg and Sinha, 2010; Whalen and Shelley, 2010; Estrada et al., 2016).

Despite these challenges, URM STEM persistence can be increased by fostering students' intellectual development, social and academic integration, and sense of belonging (Seidman, 2005; Thayer, 2000). Successful practices that increase retention through building student confidence and motivation include structured first-year programs, collaborative learning workshops, learning communities, and mentorship/counseling (Fullilove and Treisman, 1990; Duncan and Dick, 2000; Villarejo et al., 2008; Graham et al., 2013). Participation in undergraduate research can also significantly increase STEM persistence (Astin and Astin, 1993; Schultz et al., 2011; Eagan et al., 2013). These practices form the foundation of many successful academic support programs, including the University of MarylandBaltimore County (UMBC) Meyerhoff Scholars Program (Maton et al., 2012, 2016), the Biology Scholars Program at the University of California, Berkeley (Matsui et al., 2003; Matsui, 2018), and the Program for Excellence in Education and Research in the Sciences (PEERS) at the University of California, Los Angeles (UCLA; DeAngelo and Hasson, 2009; Toven-Lindsey et al., 2015). However, while persisting in a STEM major is a first step toward a STEM career, longitudinal tracking of student outcomes following graduation is critical to truly understand the long-term impact of academic support programs. While tracking students postgraduation is challenging, one proxy for measuring postgraduation success is enrollment in graduate degree programs.

\section{URM Entry into Graduate Degree Programs}

Although programs like those described improve persistence of URM students in STEM majors, matriculation into doctoral programs lags well behind URM undergraduate STEM completion rates (Myers and Turner, 2004). For example, URM students accounted for $22 \%$ of undergraduate STEM degrees in 2016, but this number dropped to $13 \%$ for STEM master's degrees, and only $9 \%$ for STEM doctorates (NSF, 2019). This pattern suggests that persistence in STEM majors, while important, is insufficient to ensure the continuation of URM STEM graduates into pipelines leading to jobs requiring advanced degrees.

Undergraduate research, in combination with mentoring, has been shown to increase STEM persistence as well as promote entry into graduate programs, especially $\mathrm{PhD}$ programs (Villarejo et al., 2008; Junge et al., 2010; National Academies of Science, Engineering, and Medicine [NASEM], 2017). In particular, undergraduate research initiatives that include support systems like formal mentoring and being part of a community of peers make it easier for students to take advantage of oppor- tunities at their institutions and develop their identity as a scientist (Hill et al., 1999; Hurtado et al., 2009).

Given the positive outcomes of undergraduate research programs, universities are increasingly investing in such programs, particularly to broaden participation (Carlone and Johnson, 2007; Junge et al., 2010; DiBartolo et al., 2016). However, many programs require a high investment in terms of personnel and expenditures (e.g., scholarships or financial support of research), limiting the number of students who can benefit from these initiatives (Gándara and Maxwell-Jolly, 1999; DiBartolo et al., 2016). Moreover, the outcomes of these programs are often measured by STEM completion rates compared with institutional or national averages without taking into account additional student characteristics that may influence the outcomes (Lane, 2016). Ideally, undergraduate research programs would reach large numbers of students to catalyze a more rapid change in STEM workforce diversity and would be assessed in a way that demonstrates long-term impacts while controlling for student and institutional characteristics that may shape results with respect to institutional and national averages.

This study examines the long-term outcomes of PEERS, a 2-year academic support program at UCLA for incoming freshman life and physical science majors from underrepresented and underserved backgrounds. Toven-Lindsey et al. (2015) used matched comparison groups to demonstrate significant positive outcomes of PEERS students, including higher academic achievement in introductory science courses and higher STEM persistence rates. Here, we follow up on this prior research, critically evaluating the long-term outcomes of these specific cohorts of PEERS students by examining participation in undergraduate research, STEM degree attainment, and entry to graduate programs.

\section{UCLA Context and the PEERS Program}

UCLA is a highly selective research university in Southern California with an undergraduate enrollment exceeding 30,000 students. Graduation rates for freshman (6-year rate) and transfer students (4-year rate) exceed $90 \%$ overall, with 6-year graduation rates for underrepresented minority students (African American, Hispanic, and Native American) averaging 85.6\% from 2013 to 2016.

In $2009,37.5 \%$ of white and Asian-American students completed their STEM degrees after 5 years nationally, while the average completion rates for black/African-American, Latino/a, and Native American students were 22.1, 18.4, and 18.8\%, respectively (Hurtado et al., 2010). Although, at 39\%, the STEM persistence rate of UCLA URM students is nearly double the national average for URM STEM persistence and is close to the national average of $40 \%$ for all students, it is still significantly lower than the 70\% STEM persistence rate of non-URM students at UCLA (Griffith, 2010; Hurtado and Sork, 2015; NASEM, 2016).

The PEERS program was established in 2003 to address this disparity in URM STEM persistence at UCLA, with the goal of improving outcomes for life and physical sciences majors from underrepresented backgrounds by adopting best practices from research related to students' first-year experience and transition to college (Barefoot et al., 2005; Reason et al., 2006). By 2009, PEERS achieved its current program structure and pedagogical model, comprising the following: PEERS begins in the Fall 
quarter of the freshman year and over 2 years provides participants with: 1) a seminar course for first-year students focused on academic skills and transitioning to college and a seminar course for second-year students focused on career development; 2) individualized holistic academic counseling; 3) collaborative-learning workshops to support introductory math, chemistry, and physics courses (Fullilove and Treisman, 1990; Treisman, 1992); and 4) twice-quarterly research seminars that expose students to the diversity of research enterprise at UCLA.

All PEERS programming is restricted to PEERS students, including the two seminars. Although there are no formal peer-mentoring programs, PEERS programing does foster nearpeer interactions at the PEERS research talks. In addition, PEERS alumni participate in panel discussions during both seminar courses, as well as through lab tours and poster sessions that are part of these courses. This programming exposes PEERS students to diverse role models such that PEERS participants will encounter on average two to three diverse professionals per month.

To reach the largest number of students possible, PEERS does not include undergraduate research as part of student programming; participation in undergraduate research is not required of PEERS students and the PEERS program does not place students into research labs. Instead, PEERS encourages students to explore undergraduate research 1) by exposing firstand second-year students to faculty research talks, 2) through poster sessions featuring the work of undergraduate researchers, and 3) through panel discussions focused on the experiences of undergraduate researchers at UCLA. In addition, as part of the PEERS sophomore seminar course, students are given the tools they need to find a research mentor by guiding students through the process of drafting a curriculum vitae and coaching them on how to reach out to potential faculty research mentors.

Previous studies (DeAngelo and Hasson, 2009; Toven-Lindsey et al., 2015) showed that PEERS students achieve higher grades in most "gatekeeper" chemistry and mathematics courses and persist through sophomore year in science majors at significantly higher rates than control groups. Additionally, PEERS students have higher GPAs at the end of the second year despite taking more science courses than the control group.

While these early positive outcomes of PEERS are important, they do not provide critical information on whether this early success translates into improved long-term outcomes that will impact entry into the STEM workforce. In this study, we follow up on Toven-Lindsey et al. (2015) by examining the long-term impact of PEERS on students in the 2009 and 2010 cohorts. Specifically, we examine whether programming that highlights the benefits of undergraduate research results in increased participation in undergraduate research. In addition, we test whether participation in PEERS has long-term benefits, including higher STEM graduation rates and higher matriculation into advanced degree programs.

\section{METHODS}

\section{Sample Population}

Our PEERS study population consists of 141 students who participated in PEERS for 2 years, entering as freshmen either in 2009 or 2010. Because students are admitted to PEERS through an application process, we created a propensity-matched control group, a statistical method applied commonly used to account for self-selection bias in studies in which fully randomized study design is not possible (Rubin, 2006; Guo and Fraser, 2010). As described in Toven-Lindsey et al. (2015), we created this propensity-matched control $(n=141)$ using propensity score analysis combined with binary logistic regression of key PEERS eligibility criteria: 1) incoming science major, 2) Scholastic Aptitude Test (SAT) math score, and 3) a composite value of "life challenge" factors. With a scale of 0 to 12 , this composite measure is generated for all UCLA undergraduate applicants using institutional data on high school characteristics, parental income and education, and other relevant background variables for internal monitoring and the development of student support programs and services. The use of the life challenges composite variable allowed us to propensity match students on a metric that encompasses a variety of socioeconomic parameters to ensure that results are not driven by underlying socioeconomic disparities. In addition, this method of defining a propensity-matched control casts the widest net, allowing us to compare the PEERS students with very similarly prepared students.

In addition to the propensity-matched control group, we also created two broader comparison groups of students who entered UCLA as freshmen in 2009 or 2010. These groups included 1$)$ all other non-URM STEM majors $(N=2670)$ and 2$)$ all other URM STEM majors $(N=807)$. We excluded data from 181 students who matriculated as science majors at UCLA in 2009 or 2010 but for whom no ethnicity information was available.

\section{Data Sources}

Student information was collected from existing campus resources, including registrar data, research center data (on research program participation), UCLA senior survey data, and National Clearinghouse data. All variables used and their sources and coding are described in the codebook in the Supplemental Material.

Registrar data were available for all students and contained information on time to degree, major, courses completed, sex, high school GPA (HS GPA), math SAT, and Pell recipient status. Completing an undergraduate science degree was measured using institutional data on student enrollment and degree conferral by Fall 2016 and is based on a timeline of 6 years to degree completion.

Undergraduate research participation was measured in three ways. First, we used records from the UCLA Undergraduate Research Center-Sciences, which administers all formal undergraduate research experience programs at UCLA, including summer research experiences and mentored research for course credit. The center tracks student participation in undergraduate research, maintaining a database on application to and participation in any of the undergraduate research programs at UCLA. Second, we used registrar data on participation in mentored research for course credit, as these "courses" have distinct numbers that can be identified on student transcripts. Third, we used student-reported data from the UCLA senior survey, a survey that UCLA students must complete to receive tickets to the graduation ceremony, so response rates are fairly high, averaging 68.3\%. This survey asks students whether they have during their time at UCLA: 1) assisted UCLA faculty in research for pay, 2) assisted UCLA faculty in research as a volunteer, and 
3) assisted faculty at another university with research for pay or as a volunteer. Students who appeared in the Undergraduate Research Center-Sciences database, received course credit for undergraduate research, or answered yes to any of the three questions on the Senior Survey were coded as having participated in undergraduate research. The remainder were coded as having not participated in undergraduate research.

To examine long-term outcomes of PEERS, we tracked student enrollment into graduate programs using National Clearinghouse data. Specifically, we used data from 2016 to capture information about matriculation into graduate or professional school between 2 and 4 years after students completed their undergraduate degrees, depending on their timelines for degree completion. Although some students may have entered graduate programs after 2016, we used 2016 for consistency and to represent timely matriculation into graduate programs (i.e., immediately or soon after completion of undergraduate degree programs). Due to the effort involved, we limited comparison of National Clearinghouse data to PEERS students and the propensity-matched control group.

We coded students' matriculation into graduate programs as a binary "yes" (currently enrolled or graduated) or "no" (never enrolled) for any graduate or professional degree programs (details in codebook in Supplemental Material). Students enrolling exclusively in extension courses or other undergraduate courses after graduation were not coded as having enrolled in graduate school. Because some institutions (mostly medical schools) do not list the degree objective in the data they report to the National Clearinghouse, we created an "unknown graduate degree" variable.

\section{Data Analysis}

We conducted all statistical analyses in SPSS (IBM), including descriptive statistics, nonparametric tests, mean score comparisons, and logistic regression. To compare mean time to degree completion, we used a one-way analysis of variance (ANOVA) with Bonferroni correction for multiple comparisons (Tabachnick and Fidell, 2013). To test for differences between comparison groups in terms of STEM degree completion, participation in research, and graduate degree enrollment between groups, we used a nonparametric chi-square with Bonferroni correction. Finally, to determine the power of specific student characteristics to predict science degree completion, undergraduate research participation, and matriculation to graduate school, we performed logistic regressions in a stepwise manner, using student background characteristic variables (sex; math SAT; HS GPA; URM; and low socioeconomic status [SES], as defined through Pell grant recipient as a proxy) in the first step of the model, and participation in PEERS or undergraduate research in the second step. Logistic regressions were either performed on a sample including PEERS and propensity-matched comparison students or all students including other URM and other non-URM as indicated. Cases with missing data were excluded from regression analyses.

\section{RESULTS}

We obtained data on all incoming life and physical science majors at UCLA who matriculated during either Fall 2009 or Fall $2010(N=3759)$, with a particular focus on students who participated in the PEERS program $(N=141)$ and a propensity-matched control $(N=141)$. In total, $92 \%$ of these students had completed their degree at the time of this study. The PEERS treatment group and propensity-matched control groups were statistically indistinguishable in terms of sex composition ( $68.8 \%$ vs. $68.1 \%$ female), $\chi^{2}(3, N=3759)=25.5, p=1.000$; percentage URM $(78.7 \%$ vs. $79.4 \%), \chi^{2}(1, N=282)=0.021, p=$ 0.884 ; HS GPA (4.30 vs. 4.28), ANOVA, $p=1.000$; math SAT score (621 vs. 622 ), ANOVA, $p=1.000$; and numbers of Pell Grant recipients (41.3\% vs. 44.8\%), $\chi^{2}(3, N=2569)=99.0, p=$ 1.000. While the other URM comparison group had a higher overall percentage (100\%) of URM students (by definition), it also had similar sex composition, lower HS GPA (4.21), ANOVA, $p=0.014$; lower math SAT scores (576), ANOVA, $p=0.000$; and a slightly lower percentage of Pell Grant recipients (35.9\%), $\chi^{2}(3, N=2569)=99.0, p=1.000$, than PEERS students. The "other non-URM" group was the most different to the PEERS group, having no URM students (by definition), a slightly higher HS GPA (4.33), ANOVA, $p=1.000$; significantly higher math SAT scores (691), ANOVA, $p=0.000$; and significantly fewer Pell Grant recipients $(19.6 \%), \chi^{2}(3, N=2569)=99.0, p=0.000$. Group compositions are summarized in Table 1.

The time to degree for all groups averaged 4.20 years (range 4.17-4.32 years). While PEERS students graduated slightly faster than control groups, there were no significant differences in time to degree when comparing PEERS students with the propensity-matched control, other URM students, and other non-URM students, ANOVA, $p=0.906, p=0.478$, and $p=$ 1.000 , respectively. However, other non-URM students had a significantly faster time to degree than the propensity-matched control and other URM comparison groups, ANOVA, $p=0.000$ and $p=0.005$ respectively (Table 1 and Supplemental Figure 1).

\section{Participation in PEERS Is Correlated with Higher Research Engagement}

Despite the fact that undergraduate research is not part of PEERS programmatic activities, significantly more PEERS students participated in undergraduate research $(77 \%), \chi^{2}(3$, $N=2598)=64.42, p=0.000)$, compared with the

TABLE 1. Demographics of study sample, by group

\begin{tabular}{lcccccc}
\hline & Female \% & URM \% & HS GPA (SD) & Math SAT (SD) & $\begin{array}{c}\text { Pell Grant } \\
\text { recipient \% }\end{array}$ & $\begin{array}{c}\text { Time to degree } \\
\text { in years (SD) }\end{array}$ \\
\hline PEERS $(N=141)$ & 68.8 & 78.7 & $4.30(0.25)$ & $621(67)$ & 41.3 & $4.23(0.50)$ \\
Matched control $(N=141)$ & 68.1 & 79.4 & $4.28(0.24)$ & $622(61)$ & 44.8 & $4.32(0.60)$ \\
Other URM $(N=807)$ & 67.3 & 100.0 & $4.21(0.34)$ & $576(89)$ & 35.9 & $4.32(0.58)$ \\
Other non-URM $(N=2670)$ & 58.8 & 0.0 & $4.33(0.33)$ & $691(72)$ & 19.6 & $4.17(0.49)$ \\
All $(N=3759)$ & 61.3 & 27.4 & $4.30(0.33)$ & $661(89)$ & 25.0 & $4.20(0.52)$ \\
\hline
\end{tabular}




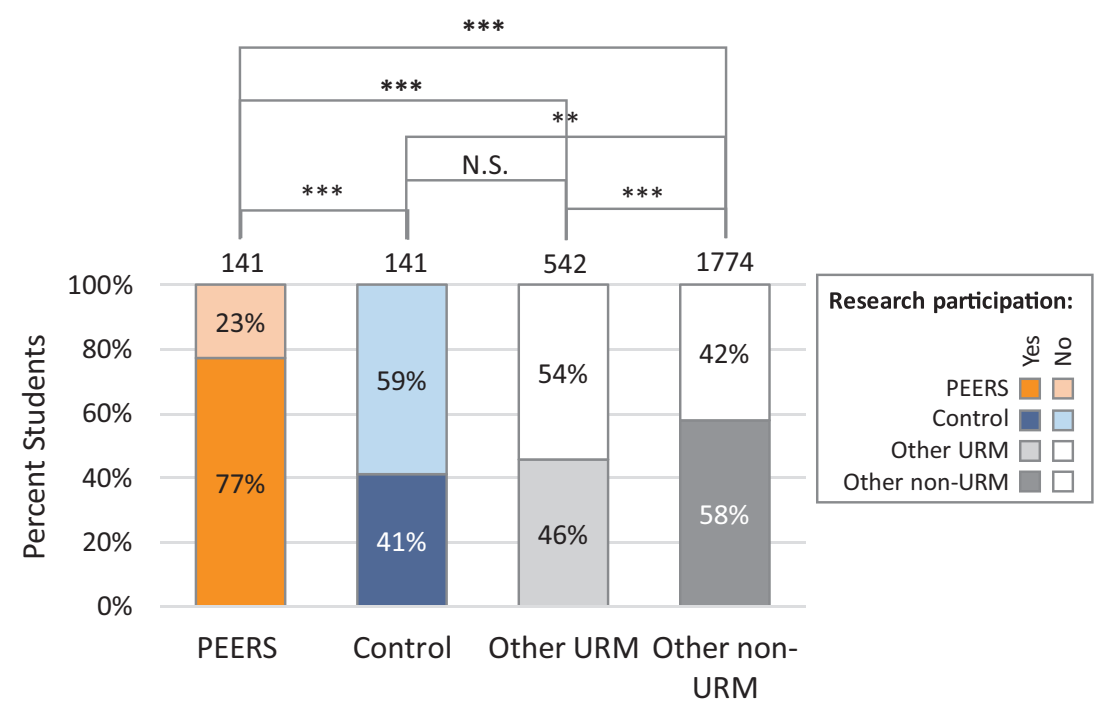

FIGURE 1. Participation rates in undergraduate research by comparison groups. Colors as shown in the legend indicate participation in undergraduate research (Yes) or no participation (No). Numbers on top of bars indicate sample group size. Pairwise comparisons for students with degrees awarded between groups were conducted using a chi-square test with Bonferroni correction; significance values are indicated (see also Supplemental Tables 1 and 2). ${ }^{* *} p<0.01$; ${ }^{* * *} p<0.001$; N.S., not significant.

a research paper (Figure 2 and Supplemental Table 4). It is particularly noteworthy that $29 \%$ of PEERS students presented their work outside of UCLA, compared with $9-11 \%$ of students in the other groups. Additionally, $15 \%$ of PEERS students indicated that their undergraduate research led to coauthorship on a scientific publication, a level that is only matched by the other non-URM students at 14\% (Figure 2).

\section{PEERS Students Graduate in Science Majors at Higher Rates}

Significantly more PEERS students graduated with a science degree (Figure 3 and Supplemental Table 5), with $72 \%$ of PEERS earning a science degree compared with $52 \%$ of students in the propensity-matched control, $\chi^{2}(3, N=3485)=189.5, p=0.001$, and $39 \%$ of other URM students, $p=0.000$. However, there was no significant difference $(p>0.05)$ between STEM graduation rates for PEERS and non-URM students who had a 70\% STEM degree completion rate.

When only examining PEERS students and the propensity-matched control, the logistic regression model revealed that HS GPA and

propensity-matched control group (41\%), other URM students (46\%) and other non-URM students (58\%; Figure 1 and Supplemental Tables 1 and 2). Logistic regression models with research participation as the dependent variable showed that PEERS participation is a positive and significant predictor for participation in undergraduate research when comparing PEERS with propensity-matched control students (Table 2) and with all other students in the sample (Supplemental Table 3).

Further evidence of high engagement of PEERS students in undergraduate research comes from senior survey data. PEERS students were significantly more likely than the propensity-matched control group to respond that they have participated in highly engaged practices such as doing oral or poster presentations on their research outside of UCLA, $\chi^{2}(3, N=$ $2501)=30.9, p=0.003$, receiving scholarships for undergraduate research, $\chi^{2}(3, N=2485)=47.1, p=0.000$, and coauthoring participation in PEERS were the only two variables that significantly predicted science degree completion (Table 2). However, when the regression model was expanded to also include other URM and other non-URM students, math SAT and participation in undergraduate research were significant positive predictors of science degree completion, while URM status was a significant negative predictor (Supplemental Table 3). However, even in this expanded model, PEERS participation remained a significant positive predictor of science degree completion.

\section{PEERS Students Enroll in Doctoral Programs at Higher Rates}

National Clearinghouse data revealed that 50\% $(N=70)$ of PEERS students had enrolled in graduate degree programs by 2016 , compared with only $39 \%(N=55)$ from the propensity-matched control. However, this difference is not statistically

TABLE 2. Logistic regression predicting undergraduate research participation $(N=197)$ and science degree completion $(N=194)$ for $P E E R S$ and matched sample ${ }^{a}$

\begin{tabular}{|c|c|c|c|c|c|c|}
\hline & \multicolumn{3}{|c|}{ Research participation } & \multicolumn{3}{|c|}{ Science degree completion ${ }^{\mathrm{b}}$} \\
\hline & B (SE) & $\operatorname{Exp}(B)$ & $p$ & B (SE) & $\operatorname{Exp}(B)$ & $p$ \\
\hline Sex $=$ Female & $0.46(0.37)$ & 1.578 & 0.220 & $-0.84(0.44)$ & 0.430 & 0.056 \\
\hline Math SAT & $1.29(0.70)$ & 3.643 & 0.063 & $-0.34(0.82)$ & 0.710 & 0.675 \\
\hline HS GPA & $0.00(0.00)$ & 1.003 & 0.310 & $0.01(0.00)$ & 1.015 & 0.000 \\
\hline URM & $-0.08(0.45)$ & 0.927 & 0.867 & $-0.66(0.53)$ & 0.518 & 0.215 \\
\hline Low SES & $-0.1(0.34)$ & 0.904 & 0.765 & $0.45(0.36)$ & 1.570 & 0.216 \\
\hline PEERS & $1.55(0.34)$ & 4.709 & 0.000 & $0.87(0.37)$ & 2.385 & 0.018 \\
\hline Undergraduate research & NA & NA & NA & $0.49(0.38)$ & 1.633 & 0.194 \\
\hline Constant & $-7.64(3.66)$ & 0.000 & 0.037 & $-6.76(4.23)$ & 0.001 & 0.110 \\
\hline
\end{tabular}

aBold print indicates statistically significant values. NA, not available/does not apply.

bExcludes cases with no degree awarded or missing data. 


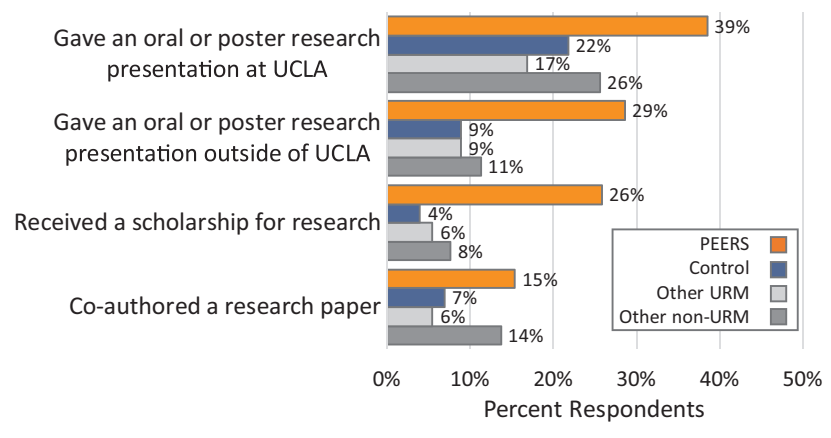

FIGURE 2. Participation rates in highly engaged research practices by comparison groups. Numbers to the right of bars represent the percent respondents from each group who had indicated "yes" to the respective survey question (see also Supplemental Table 1; significance indications are omitted from this figure to improve readability; please refer to Supplemental Table 4 for statistical significance values on pairwise comparisons).

significant, $\chi^{2}(1, N=282)=3.23, p=0.072$. The logistic regression model showed a positive effect of PEERS participation on graduate degree program enrollment (Figure 4 and Table 3), but this effect was also not significant. However, more students from the propensity-matched control enrolled in master's programs than did PEERS students $(N=30$ and $N=18$, respectively), while PEERS students were significantly more likely to matriculate into doctoral programs (46 PEERS vs. 17 propensity-matched control group); $\mathrm{PhD}:\left(\chi^{2}(1, N=282)=9.54, p=\right.$ 0.002; MD: $\left(\chi^{2}(1, N=282)=5.96, p=0.015\right.$; any doctorate (MD, PhD PharmD): $\left(\chi^{2}(1, N=282)=16.21, p=0.000\right.$. Logistic regression models showed that participation in PEERS is a significant positive predictor of enrollment in doctoral programs (Table 3).

\section{DISCUSSION}

Increasing diversity in the STEM workforce not only requires increasing low URM STEM persistence rates, but also the matriculation of URM students into graduate programs that prepare them for high-skill STEM careers (PCAST, 2012). Although the PEERS program is only a 2-year program focused on the freshman and sophomore years of entering STEM majors, this early intervention creates lasting long-term impacts, with PEERS students having shorter time to degree and higher STEM persistence rates than a propensity-matched control group. Most importantly, time to degree and STEM persistence of PEERS students equaled the non-URM comparison group, showing that early intervention can eliminate the achievement gap between URM and non-URM students.

Critically, the impact of PEERS extended beyond students' undergraduate studies, with a significantly higher number of PEERS student entering $\mathrm{PhD}, \mathrm{MD}$, and PharmD programs. A key component of this success appears to be high research engagement of PEERS students, which exceeded all comparison groups, including non-URM students. It is well established that research engagement is a strong driver of STEM degree completion as well as matriculation into graduate programs (NRC, 2007; Seymour et al., 2004; McGee and Keller, 2007; McGee et al., 2012; Russell et al., 2007; NASEM, 2016, 2017; Rodenbusch et al., 2016), so our results are perhaps expected. However, unlike many programs that include undergraduate research as a formal programmatic element (Carter et al., 2009; Maton et al., 2012, 2016; Ballen and Mason, 2017), PEERS achieves these results without any formal research component. Rather, PEERS students seek out undergraduate research opportunities on their own. As such, PEERS provides an affordable and scalable model to support large numbers of students, maximizing impact on STEM diversity at relatively minimal cost.

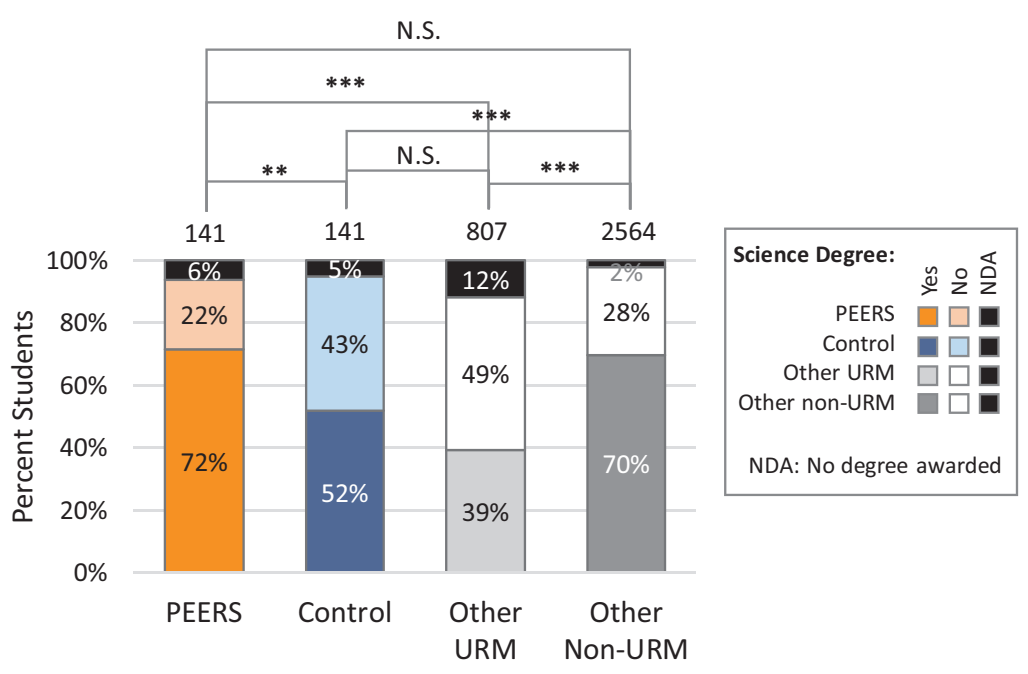

FIGURE 3. Degree completion rates by comparison groups. Colors as shown in the legend indicate completion of a science degree (Yes), non-science degree (No), or no degree at the time of data collection (NDA). Numbers on top of bars indicate sample group size. Pairwise comparisons for students with degrees awarded between groups were conducted using a chi-square test; significance values are indicated (see also Supplemental Table 5). ${ }^{* *} p<0.01 ;{ }^{* *} p<0.001$; N.S., not significant.

\section{Entry to Research}

Participation in undergraduate research is a wellknown driver of STEM success, persistence, matriculation to graduate school, and STEM careers (Lopatto, 2004, 2007; Rodenbusch et al., 2016; Estrada et al., 2018). For example, when asked to reflect on their path to success, STEM professionals indicate that undergraduate research was a formative experience (Estrada et al., 2018). Surveys also show that undergraduate research increased student expectations of pursuing a PhD (Russel et al., 2007) as well as their likelihood of attending graduate (Bauer and Bennett, 2003) or medical school (Vincent-Ruz et al., 2018). Importantly, these effects can be particularly profound for URM students (Foertsch et al., 2000). As such, there are national efforts to increase participation in undergraduate research and to disseminate best practices (NASEM, 2017).

PEERS students had the highest levels of undergraduate research engagement of any comparison group. They were almost twice as likely as the propensity-matched control group and 33\% more likely than non-URM students to engage in undergraduate research. Given the demonstrated strong 


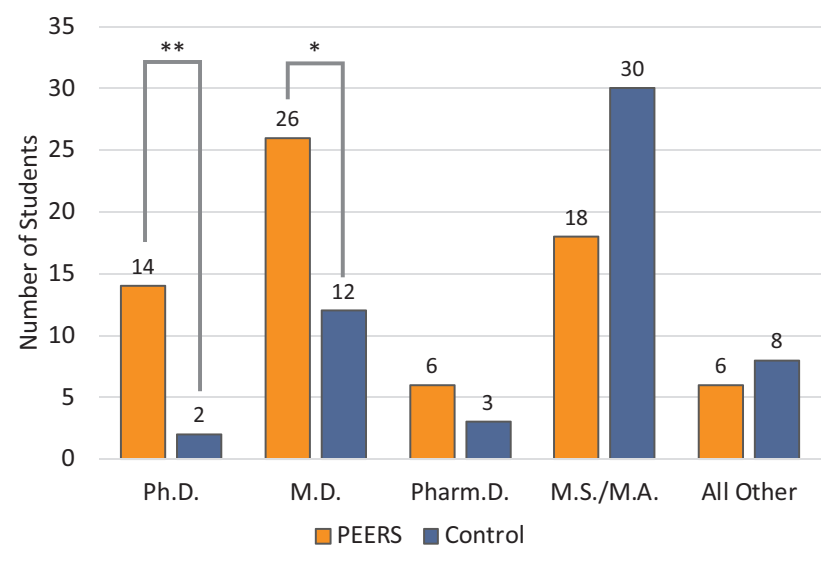

FIGURE 4. Enrollment in graduate degree programs for PEERS and propensity-matched control students. Numbers above bars indicate numbers of students currently enrolled or having completed the indicated degree. "All Other" includes JD, DDS, MSN, MPH, and unknown programs. PhD and MD enrollments were significantly different between PEERS and control students; all other pairwise comparisons were not significantly different (chi-square). ${ }^{*} p<0.05 ;{ }^{* *} p<0.01$.

benefits of undergraduate research noted earlier, it is perhaps not surprising that PEERS students have high STEM persistence, lower time to degree completion, and higher entry into graduate school. What is surprising, however, is that PEERS achieves these outcomes without having undergraduate research as part of its curriculum.

The high research engagement of PEERS students comes from merely priming and encouraging PEERS participants to explore undergraduate research, rather than directly funding students to do research, providing structured research activities, or actively placing students in labs. This priming consists of strategies focused on providing diverse role models who demonstrate both the value of undergraduate research experiences as well as a pathway. Students hear from PEERS alumni about their experiences as undergraduate researchers and how that experience impacted their studies and career ambitions. They attend poster sessions where they see PEERS alumni present their research on a wide diversity of topics ranging from ecology and environmental science to molecular biology and medical research. Finally, we schedule six research seminars by diverse UCLA faculty who talk about their research and their paths to being in research careers in language appropriate for freshmen. This exposure shapes student aspirations while providing a path toward realizing those aspirations.

In addition to priming students to consider engaging in undergraduate research, PEERS also provides the tools to help them navigate the process of finding a lab for a mentored undergraduate research experience. In a one-unit sophomore seminar course that totals only 10 contact hours, PEERS students are asked to identify labs doing research that interests them. We then instruct students on how to prepare a curriculum vitae, cover letter, and introductory email. Graduate students and faculty then provide feedback to make those documents as strong as possible. Importantly, we tell PEERS students to expect many rejections, but that their persistence will eventually be rewarded with success. Such coaching/mindset interventions can dramatically improve persistence (Bettinger and Baker, 2011; Walton and Cohen, 2011), which could partially explain the high persistence of PEERS students in STEM majors and the high numbers of students landing positions in research labs. The fact that they pursued and earned these research opportunities on their own likely builds confidence and shapes their perceptions of themselves as scientists.

\section{Persistence and Time to Degree}

Despite dedicated efforts to increase diversity in STEM fields, STEM diversity remains low (NASEM, 2011; Estrada et al., 2016), and in some fields has remained unchanged over decades (Bernard and Cooperdock, 2018). This pattern is largely due to the fact that only about half of students entering STEM degree programs nationwide complete a STEM degree (Chen and Soldner, 2013) and persistence for URM students is about half this national average (Hurtado et al., 2010). As such, a major focal point of increasing STEM diversity is increasing persistence of URM STEM majors (Estrada et al., 2016).

In a previous study, Toven-Lindsey et al. (2015) showed that participation in PEERS significantly increased persistence of URM STEM majors through the end of the second year, the time at UCLA when students are most likely to leave STEM majors. Here, we demonstrate that this elevated 2-year STEM persistence extends through graduation, with PEERS students completing STEM degrees at rates similar to non-URM students

TABLE 3. Logistic regression predicting matriculation into graduate degree programs $(N=197)$ and doctoral programs $(N=197)$ for PEERS and matched sample ${ }^{a}$

\begin{tabular}{|c|c|c|c|c|c|c|}
\hline & \multicolumn{3}{|c|}{ Graduate degree program } & \multicolumn{3}{|c|}{ Doctoral program $^{\text {b }}$} \\
\hline & $\mathrm{B}(\mathrm{SE})$ & $\operatorname{Exp}(\mathrm{B})$ & $p$ & $\mathrm{~B}(\mathrm{SE})$ & $\operatorname{Exp}(B)$ & $p$ \\
\hline Sex $=$ Female & $0.19(0.35)$ & 1.215 & 0.579 & $-0.12(0.42)$ & 0.888 & 0.775 \\
\hline Math SAT & $1.66(0.71)$ & 5.257 & 0.020 & $0.99(0.85)$ & 2.689 & 0.247 \\
\hline HS GPA & $0.01(0.00)$ & 1.005 & 0.052 & $0.01(0.00)$ & 1.011 & 0.002 \\
\hline URM & $0.11(0.42)$ & 1.120 & 0.787 & $0.02(0.51)$ & 1.024 & 0.964 \\
\hline LOW SES & $-0.22(0.32)$ & 0.801 & 0.483 & $0.03(0.41)$ & 1.028 & 0.947 \\
\hline PEERS & $0.28(0.32)$ & 1.322 & 0.379 & $1.15(0.42)$ & 3.166 & 0.006 \\
\hline Undergraduate research & $0.44(0.33)$ & 1.545 & 0.191 & $0.44(0.46)$ & 1.546 & 0.348 \\
\hline Constant & $-11.07(3.67)$ & 0.000 & 0.003 & $-13.18(4.56)$ & 0.000 & 0.004 \\
\hline
\end{tabular}

abold print indicates statistically significant values. NA, not available/does not apply.

${ }^{\mathrm{b}} \mathrm{PhD}, \mathrm{MD}$, or PharmD. 
(72 and 70\%, respectively) and at rates significantly higher than the propensity-matched control and other URM students (52 and 39\%, respectively).

Science persistence is strongly related to students' academic success and motivation (Lane, 2016), so higher science grades and GPAs could result in higher persistence rates. As such, Toven-Lindsey et al. (2015) partially attributed the increased 2-year STEM persistence rates of PEERS students to higher GPAs and higher grades in foundational math and science. These higher grades are achieved by implementation of Treisman-style workshops, as well as individualized academic counseling and college success seminars in a cohort-based program, factors shown to improve academic success (Duncan and Dick, 2000). Therefore, if these impacts persist beyond student involvement in PEERS, higher STEM persistence of PEERS students could be explained by higher grades, particularly during their formative early years of study.

Regression analysis shows that HS GPA was a minor positive predictor of science degree completion, providing a possible explanation for the success of PEERS students. However, PEERS students and the propensity-matched control had statistically indistinguishable HS GPAs, despite PEERS students having a science degree completion rate that exceeded all other comparison groups, including non-URM students. Similarly, while PEERS students had a marginally higher GPA at graduation in comparison to the propensity-matched control, this difference was also not significant. Despite having high school and college GPAs equivalent to the propensity-matched control, PEERS STEM persistence was equal to non-URM students, even though non-URM group had the highest GPA at graduation. As such, it is unlikely that higher persistence rates of PEERS students can be simply attributed to high school preparation or grades in college. Instead, higher STEM persistence is most likely due to the effects of the program itself.

While our results indicate a strong effect of PEERS on student outcomes, it is important to consider the possibility that these results stem from self-selection bias, with PEERS composed of students who were motivated to apply for and join the program. However, the propensity matching used in our control is designed to compensate for such self-selection bias (Rubin, 2006; Guo and Fraser, 2010), eliminating self-selection as a likely driver of our results. Similarly, because PEERS provides a cohort-type experience that has been shown to improve outcomes for URM college students (Toven-Lindsey et al., 2015), it is possible that PEERS students persist because this cohort experience results in a better student experience and higher student satisfaction. To test this possibility post hoc, we compared student satisfaction with their undergraduate experience using data from the UCLA College Senior Survey. Results indicated that students in this study were generally satisfied with their academic experience, campus life, and overall college experience with no significant differences between groups (Supplemental Table 6).

\section{Enrollment in Graduate Programs}

Given the links between undergraduate research and matriculation to graduate school (Rodenbusch et al., 2016; Estrada et al., 2018), we would expect PEERS students to have significantly higher matriculation rates into graduate programs, as PEERS students were almost twice as likely to engage in undergradu- ate research compared with the propensity-matched control. Surprisingly, however, while PEERS students were 25\% more likely to engage in undergraduate research than the control, this difference did not translate into significantly higher enrollment into graduate programs. Yet, important differences were observed-PEERS students were significantly more likely to enroll into $\mathrm{PhD}$ and other doctoral programs, while students in the propensity-matched control were more likely to enroll in master's programs. This difference likely indicates a difference both in student self-perception and aspiration.

Insights into this result come from the Senior Survey data that show that PEERS students were highly engaged in their undergraduate research experiences (Figure 4). PEERS students were nearly twice as likely to present their research at UCLA, three times more likely to present at a conference outside of UCLA, nearly seven times more likely to receive scholarships to pursue research, and twice as likely to publish their research. All these factors likely make students more competitive for doctoral degree programs, as most $\mathrm{PhD}, \mathrm{MD}$, and PharmD programs highly value undergraduate research experiences in their admissions decisions. Moreover, these experiences likely have a profound impact on student confidence and self-perception as scientists. These factors may make PEERS students more inclined to pursue doctoral, rather than master's degree programs, an area of inquiry that merits further study.

Outcomes for PEERS students were similar to those of other programs with research programming that often include significant financial incentives. For example, the SURE program at Emory University is a structured residential summer research program that reports $16 \%$ of the completers enroll in $\mathrm{PhD}$ programs and 30\% in MD programs (Junge et al., 2010). These rates are comparable to those of PEERS students, of whom $10 \%$ enrolled in $\mathrm{PhD}$ programs and $18 \%$ in MD programs. Similarly, the Meyerhoff Program reports that participants are 5.3 times more likely than nonparticipants to enter a $\mathrm{PhD}$ program, which is also comparable with the PEERS program where the ratio is approximately seven times (Maton et al., 2012, 2016). However, PEERS achieves these results with only exposure to research and support services without residential experiences or other financial incentives, making PEERS a much less expensive model and creating the possibility of reaching more students.

It is important to note that our data on matriculation to graduate programs come exclusively from National Clearinghouse data. As such, it is not possible to examine how many students applied to graduate school, or whether students who applied to master's programs did so as a stepping-stone to other advanced graduate degrees. However, the fact that more students in PEERS immediately apply to $\mathrm{PhD}$ and $\mathrm{MD}$ programs indicates that the program provides them the skills and confidence to directly pursue these advanced degrees upon graduation.

\section{Scalability of the PEERS Model}

Data from NSF indicate that URMs obtained $21.6 \%$ of all STEM degrees awarded in 2016 and that, at current rates of increase, URM students will earn STEM degrees at rates proportional to their percentage in the U.S. population in a little more than a decade (NSF, 2019). In contrast, URMs only earned $8.8 \%$ of doctoral degrees in 2016; at current rates it will be $\sim 30$ years 
before representation of URMs at the doctoral level matches national demographics. With URMs only representing $8.9 \%$ of the physician workforce in 2014 and $14.9 \%$ of medical school degrees in 2012, similar arguments can be made for MDs (Nivet and Castillo-Page, 2014). As such, it is imperative that we increase the rate at which diverse students enter STEM and medical degree programs. Achieving that goal requires strategies that can reach larger numbers of students and maximize the success of those students.

There are many excellent cohort-based academic support programs that improve research engagement, including the UMBC Meyerhoff Scholars Program (Carter et al., 2009), the Biology Undergraduate Scholars Program at UC Davis (Villarejo et al., 2008), and the Comprehensive STEM Program at Jefferson University (Lane, 2016), among others. However, aspects of these programs often include financial support, summer bridge programs, and placement into research labs, making them costly to implement and difficult to scale (Gándara and Maxwell-Jolly, 1999). As a result, while students in these and other programs are very successful, there is a limit to how many students such programs can reach, curtailing their ability to significantly impact the demographics of the U.S. STEM workforce.

In contrast, the interventions employed in the PEERS program do not involve financial support, residential bridge programs, or placing students into research labs. Instead, our focus is on interventions that support early academic success and inspire and empower students to engage in undergraduate research on their own. As such, this model is easy to scale for large populations of students while still being cost-effective. Indeed, in 2016, the PEERS program increased in size from $60-80$ students per cohort to $200-220$ students per cohort. The strategies used by PEERS could serve as a viable model to other institutions seeking to support the success of large numbers of diverse students at a modest cost.

\section{CONCLUSION}

The U.S. and undergraduate populations have become increasingly diverse (NSF, 2020), and there are increasing calls for equity in higher education (Barber et al., 2020) to achieve the goals of a diversified U.S. STEM workforce (National Science and Technology Council, 2018). While the impact of resource-intensive programs like Meyerhoff is clear, leading to efforts to replicate its success (Sto Domingo et al., 2019), the cost of such programs may represent a significant barrier to broadscale implementation, particularly as funding for higher education continues to decrease (Mitchell et al., 2017). Given these financial realities, low-cost, high-impact programs like PEERS may be preferable for many universities looking to maximize the success of URM students for relatively minimal costs. Unless we maximize the number of successful URM students, diversity in the U.S. STEM enterprise will continue to be lacking.

\section{ACKNOWLEDGMENTS}

The PEERS program is indebted to C. Buchanan and R. Weiss for their vision and leadership and to the PEERS advisory board members for their guidance. We thank the Division of Undergraduate Education at UCLA for their ongoing support of the PEERS Program. Research was supported by an award from the National Institute of General Medical Sciences of the National Institutes of
Health under award number R25GM055052. Prior work on this project was supported by a Howard Hughes Medical Institute Undergraduate Science Education Grant (Eiserling, principal investigator). This research was approved by UCLA's Institutional Review Board (IRB no. 11.000049).

\section{REFERENCES}

Allen-Ramdial, S.-A. A., \& Campbell, A. G. (2014). Reimagining the pipeline: Advancing STEM diversity, persistence, and success. BioScience, 64(7), 612-618. doi: 10.1093/biosci/biu076

Astin, A. W., \& Astin, H. S. (1993). Undergraduate science education: The impact of different college environments on the educational pipeline in the sciences. National Science Foundation,

Ballen, C. J., \& Mason, N. A. (2017). Longitudinal analysis of a diversity support program in biology: A national call for further assessment. BioScience, 67, 367-373. doi: 10.1093/biosci/biw187

Barber, P. H., Hayes, T. B., Johnson, T. L., \& Márquez-Magaña, L. (2020). Systemic racism in higher education. Science, 369(6510), 1440-1441. doi: 10.1126/science.abd7140

Barefoot, B., Gardner, J., Cutright, M., Morris, L., Schroeder, C., Siegel, M., ... \& Swing, R. (2005). Achieving and sustaining institutional excellence for the first year of college. San Francisco: Jossey-Bass.

Bauer, K. W., \& Bennett, J. S. (2003). Alumni perceptions used to assess undergraduate research experience. Journal of Higher Education, 74, 210.

Beasley, M. A., \& Fischer, M. J. (2012). Why they leave: The impact of stereotype threat on the attrition of women and minorities from science, math and engineering majors. Social Psychology of Education, 15(4), 427-448. doi: $10.1007 / \mathrm{s} 11218-012-9185-3$

Bernard, R. E., \& Cooperdock, E. H. (2018). No progress on diversity in 40 years. Nature Geoscience, 11, 292-295.

Bettinger, E., \& Baker, R. (2011). The effects of student coaching in college: An evaluation of a randomized experiment in student mentoring (National Bureau of Economic Research Working Paper Series No. 16881). Cambridge, MA: National Bureau of Economic Research. doi: 10.3386/w16881

Carlone, H. B., \& Johnson, A. (2007). Understanding the science experiences of successful women of color: Science identity as an analytic lens. Journal of Research in Science Teaching, 44(8), 1187-1218. doi: 10.1002/ tea.20237

Carter, F. D., Mandell, M., \& Maton, K. I. (2009). The influence of on-campus, academic year undergraduate research on STEM Ph.D. outcomes: Evidence from the Meyerhoff Scholarship Program. Educational Evaluation and Policy Analysis, 31, 441-462. doi: DOi 10.3102/0162373709348584

Chavira, G., Cooper, C. R., \& Vasquez-Salgado, Y. (2016). Pathways to achievement: Career and educational aspirations and expectations of latina/o immigrant parents and early adolescents. Journal of Latinos and Education, 15(3), 214-228. doi: 10.1080/15348431.2015.1131693

Chen, X., \& Soldner, M. (2013). STEM attrition: College students' paths into and out of STEM fields: Statistical analysis report (NCES 2014-001). Washington, DC: U.S. Department of Education.

Choy, S. P., Horn, L. J., Nuñez, A. M., \& Chen, X. (2000). Transition to college: What helps at-risk students and students whose parents did not attend college. New Directions for Institutional Research, 2000(107), 45-63. doi: dOi:10.1002/ir.10704

Crisp, G., Nora, A., \& Taggart, A. (2009). Student characteristics, pre-college, college, and environmental factors as predictors of majoring in and earning a STEM degree: An analysis of students attending a Hispanic serving institution. American Educational Research Journal, 46(4), 924 942. doi: 10.3102/0002831209349460

DeAngelo, L., \& Hasson, T. (2009). Quantifying success: Using control groups to measure program effectiveness. CUR Quarterly, 29(3), 39-45.

DiBartolo, P. M., Gregg-Jolly, L., Gross, D., Manduca, C. A., Iverson, E., Cooke, D. B., ... \& Swartz, J. E. (2016). Principles and practices fostering inclusive excellence: lessons from the Howard Hughes Medical Institute's Capstone Institutions. CBE-Life Sciences Education, 15(3), ar44. doi: ARTN ar4410.1187/cbe.16-01-0028

Duncan, H., \& Dick, T. (2000). Collaborative workshops and student academic performance in introductory college mathematics courses: A study of 
a Treisman model math excel program. School Science and Mathematics, 100(7), 365-373.

Eagan, M. K., Hurtado, S., Chang, M. J., Garcia, G. A., Herrera, F. A., \& Garibay, J. C. (2013). Making a difference in science education: The impact of undergraduate research programs. American Educational Research Journal, 50(4), 683-713. doi: 10.3102/0002831213482038

Elliott, R., Strenta, A. C., Adair, R., Matier, M., \& Scott, J. (1994). The role of ethnicity in choosing and leaving science in highly selective institutions. Research in Higher Education, 37(6), 681-709. doi: 10.1007/BF01792952

Estrada, M., Burnett, M., Campbell, A. G., Campbell, P. B., Denetclaw, W. F., Gutiérrez, C. G., ... \& Zavala, M. (2016). Improving underrepresented minority student persistence in STEM. CBE-Life Sciences Education, 15(3), es5. doi: 10.1187/cbe.16-01-0038

Estrada, M., Hernandez, P. R., \& Schultz, P. W. (2018). A longitudinal study of how quality mentorship and research experience integrate underrepresented minorities into STEM careers. CBE-Life Sciences Education, 17(1), ar9. doi: 10.1187/cbe.17-04-0066

Foertsch, J., Alexander, B. B., \& Penberthy, D. (2000). Summer research opportunity programs (SROPs) for minority undergraduates: A longitudinal study of program outcomes, 1986-1996. Council of Undergraduate Research Quarterly, 20(3), 114-119.

Fullilove, R. E., \& Treisman, P. U. (1990). Mathematics achievement among African American undergraduates at the University of California, Berkeley: An evaluation of the Mathematics Workshop Program. Journal of Negro Education, 59(3), 463-478.

Gándara, P., \& Maxwell-Jolly, J. (1999). Priming the pump: A review of programs that aim to increase the achievement of underrepresented minority undergraduates. New York: College Board. Retrieved January 21, 2021 from https://files-eric-ed-gov.libproxy1.usc.edu/fulltext/ED562803.pdf

Graham, M. J., Frederick, J., Byars-Winston, A., Hunter, A.-B., \& Handelsman, J. (2013). Increasing persistence of college students in STEM. Science, 341(6153), 1455-1456. doi: 10.1126/science.1240487

Griffith, A. L. (2010). Persistence of women and minorities in STEM field majors: Is it the school that matters? Cornell University, School of Industrial and Labor Relations. Retrieved March 8, 2019, from http://digitalcommons iltr.cornell.edu/workingpapers/122/

Guo, S., \& Fraser, M. (2010). Propensity score analysis: Statistical methods and applications (Vol. 11). Thousand Oaks, CA: Sage.

Hill, R. D., Castillo, L. G., Ngu, L. Q., \& Pepion, K. (1999). Mentoring ethnic minority students for careers in academia: The WICHE Doctoral Scholars Program. Counseling Psychologist, 2, 827-845.

Hurtado, S., Cabrera, N. L., Lin, M. H., Arellano, L., \& Espinosa, L. L. (2009). Diversifying science: Underrepresented student experiences in structured research programs. Research in Higher Education, 50(2), 189-214. doi: 10.1007/s11162-008-9114-7

Hurtado, S., Eagan, K., \& Chang, M. (2010, January). Degrees of success: Bachelor's degree completion rates among initial STEM majors (HERI research brief). Los Angeles, CA: Higher Education Research Institute at University of California, Los Angeles.

Hurtado, S., \& Sork, V. (2015). Enhancing student success and building inclusive classrooms at UCLA. Los Angeles: University of California, Los Angeles. Retrieved January 21, 2021, from http://wscuc.ucla.edu/wp-content/ uploads/2019/01/C5_16_Report_Enhancing_Student_Success_Building _Inclusive_Classrooms_at_UCLA_December_2015.pdf

Junge, B., Quiñones, C., Kakietek, J., Teodorescu, D., \& Marsteller, P. (2010). Promoting undergraduate interest, preparedness, and professional pursuit in the sciences: An outcomes evaluation of the SURE program at Emory University. CBE-Life Sciences Education, 9, 119-132. doi: 10.1187/cbe.09-08-0057

Kokkelenberg, E. C., \& Sinha, E. (2010). Who succeeds in STEM studies? An analysis of Binghamton University undergraduate students. Economics of Education Review, 29(6), 935-946. doi:10.1016/j.econedurev.2010.06.016

Lane, T. B. (2016). Beyond academic and social integration: Understanding the impact of a STEM enrichment program on the retention and degree attainment of underrepresented students. CBE-Life Sciences Education, 15(3), ar39. doi: 10.1187/cbe.16-01-0070

Lopatto, D. (2004). Survey of Undergraduate Research Experiences (SURE): First findings. Cell Biology Education, 3, 270-277. doi: 10.1187/cbe.0407-0045
Lopatto, D. (2007). Undergraduate research experiences support science career decisions and active learning. CBE-Life Sciences Education, 6(4), 297-306. doi: 10.1187/cbe.07-06-0039

Maton, K. I., Beason, T. S., Godsay, S., Sto Domingo, M. R., Bailey, T. C., Sun, S., \& Hrabowski, F. A. 3rd. (2016). Outcomes and processes in the Meyerhoff Scholars Program: STEM PhD completion, sense of community, perceived program benefit, science identity, and research self-efficacy. CBE-Life Sciences Education, 15(3), ar48. doi: 10.1187/cbe.16-01-0062

Maton, K. I., Pollard, S. A., McDougall Weise, T. V., \& Hrabowski, F. A. (2012) Meyerhoff Scholars Program: A strengths-based, institution-wide approach to increasing diversity in science, technology, engineering, and mathematics. Mount Sinai Journal of Medicine, 79(5), 610-623. doi: 10.1002/msj.21341

Matsui, J., Liu, R., \& Kane, C. (2003). Evaluating a science diversity program at UC Berkeley: More questions than answers. Cell Biology Education, 2, 117-121

Matsui, J. T. (2018). "Outsiders at the table"-Diversity lessons from the Biology Scholars Program at the University of California, Berkeley. CBE-Life Sciences Education, 17(3), es11. doi: 10.1187/cbe.17-12-0276

McGee, R., \& Keller, J. L. (2007). Identifying future scientists: Predicting persistence into research training. CBE-Life Sciences Education, 6, 316-331

McGee, R., Saran, S., \& Krulwich, T. A. (2012). Diversity in the biomedical research workforce: Developing talent. Mount Sinai Journal of Medicine, 79, 397-411. doi: 10.1002/msj.21330

Mitchell, M., Leachman, M., \& Masterson, K., Center, \& CBPP, O. B. A. P. P. (2017) A lost decade in higher education funding: State cuts have driven up tuition and reduced quality. Washington, DC: Center on Budget and Policy Priorities. Retrieved September 28, 2020, from www.cbpp.org/research/statebudget-and-tax/a-lost-decade-in-higher-education-funding

Myers, S. L., \& Turner, C. S. (2004). The effects of Ph.D. supply on minority faculty representation. AEA Papers and Proceedings, 94(2), 296-301.

National Academy of Sciences, National Academy of Engineering, and Institute of Medicine (NASEM). (2011). Expanding underrepresented minority participation. Washington, DC: National Academies Press. https://doi .org/10.17226/12984

NASEM. (2016) Barriers and opportunities for 2-year and 4-year STEM degrees: Systemic change to support students' diverse pathways. Washington, DC: National Academies Press.

NASEM. (2017). Undergraduate research experiences for STEM students: Successes, challenges, and opportunities. Washington, DC: National Academies Press.

National Science Foundation (NSF). (2019). Women, minorities and persons with disabilities in science and engineering. Alexandria, VA.

NSF. (2020). The state of U.S. science and engineering 2020. Alexandria, VA: National Center for Science and Engineering Statistics. Retrieved January 21, 2021, from https://ncses.nsf.gov/pubs/nsb20201/u-s-s-e-workforce

National Research Council (NRC). (2007). Understanding Interventions That Encourage Minorities to Pursue Research Careers: Summary of a Workshop. Washington, DC: The National Academies Press.

National Science and Technology Council. (2018). Charting a course for success: America's strategy for STEM education. Retrieved January 21, 2021, from https://www.nsf.gov/nsb/meetings/2019/0514/presentations/CS -Open-NSB-STEM-Ed-Plan-Marrongelle-Presentation.pdf

Nivet, M., \& Castillo-Page, L. (2014). Diversity in the physician workforce: Facts \& figures 2014. Washington, DC: Association of American Medical Colleges.

President's Council of Advisors on Science and Technology. (2012). Engage to excel: Producing one million additional college graduates with degrees in science, technology, engineering, and mathematics. Washington, DC: U.S. Government Office of Science and Technology.

Reason, R. D., Terenzini, P. T., \& Domingo, R. J. (2006). First things first: Developing academic competence in the first year of college. Research in Higher Education, 47(2), 149-175. doi: 10.1007/s11162-005-8884-4

Rodenbusch, S. E., Hernandez, P. R., Simmons, S. L., \& Dolan, E. L. (2016) Early engagement in course-based research increases graduation rates and completion of science, engineering, and mathematics degrees CBE-Life Sciences Education, 15(2), ar20. doi: 10.1187/cbe.16-03-0117

Rubin, D. B. (2006). Matched sampling for causal effects. New York: Cambridge University Press. 
Russell, S. H., Hancock, M. P., \& McCullough, J. (2007). The pipeline. Benefits of undergraduate research experiences. Science, 316, 548-549.

Schultz, P. W., Hernandez, P. R., Woodcock, A., Estrada, M., Chance, R. C. Aguilar, M., \& Serpe, R. T. (2011). Patching the pipeline: Reducing educational disparities in the sciences through minority training programs. Educational Evaluation and Policy Analysis, 33(1). doi: 10.3102/0162373710392371

Seidman, A. (2005). Minority student retention: Resources for practitioners. New Directions for Institutional Research, 2005(125), 7-24. doi: 10.1002/ir.136

Seymour, E., Hunter, A. B., Laursen, S. L., \& DeAntoni, T. (2004). Establishing the benefits of research experiences for undergraduates: First findings from a three-year study. Science Education, 88, 493-534.

Sto Domingo, M. R., Sharp, S., Freeman, A., Freeman, T., Harmon, K., Wiggs, M., ... \& Summers, M. F. (2019). Replicating Meyerhoff for inclusive excellence in STEM. Science, 364(6438), 335-337. doi: 10.1126/science.aar5540

Strenta, A. C., Elliott, R., Adair, R., Matier, M., \& Scott, J. (1994). Choosing and leaving science in highly selective institutions. Research in Higher Education, 35(5), 513-547.

Tabachnick, B. G., \& Fidell, L. S. (2013). Using multivariate statistics. New York, NY: Pearson.

Thayer, P. (2000). Retention of students from first generation and low income backgrounds (pp. 2-9). Washington, DC: Council for Opportunity in Education. Retrieved from ERIC (ED446633).
Toven-Lindsey, B., Levis-Fitzgerald, M., Barber, P. H., \& Hasson, T. (2015). Increasing persistence in undergraduate science majors: A model for institutional support of underrepresented students. CBE-Life Sciences Education, 14(2), ar12. doi: 10.1187/cbe.14-05 $-0082$

Treisman, U. (1992). Studying students studying calculus: A look the lives of minority mathematics students in college. College Mathematics Journal, 23(5), 362-372.

Villarejo, M., Barlow, A. E. L., Kogan, D., Veazey, B. D., \& Sweeney, J. K. (2008). Encouraging minority undergraduates to choose science careers: Career paths survey results. CBE-Life Sciences Education, 7(4), 394-409.

Vincent-Ruz, P., Grabowski, J., \& Schunn, C. D. (2018). The impact of early participation in undergraduate research experiences on multiple measures of premed path success. Scholarship and Practice of Undergraduate Research, 1(3), 13-18

Walton, G. M., \& Cohen, G. L. (2011). A brief social-belonging intervention improves academic and health outcomes of minority students. Science, 331(6023), 1447-1451.

Whalen, D. F., \& Shelley, M. C., II. (2010). Academic success for STEM and non-STEM majors. Journal of STEM Education: Innovations and research, 11(1/2), 45 